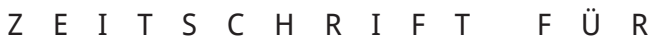

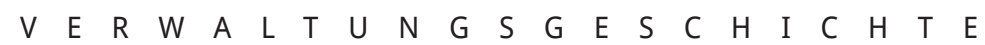

$\begin{array}{lllllllll}B & A & N & D & 4 & 2 & 0 & 1 & 9\end{array}$

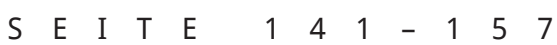

D O I : $10.2478 / \mathrm{ADH}$ I- $2019-0009$

\title{
Nelson Mandela's Archive: a Case Study in Research-driven Institutional Change Management
}

\author{
VERNE HARRIS, SHADRACK KATUU
}

\section{Introduction}

In 1999, Nelson Mandela stepped down after a 5-year term as South Africa's first democratically elected President. Within months, he founded the Nelson Mandela Foundation (NMF), a not-for-profit nongovernmental organisation (NGO) with a mandate to run his post-presidential office. In 1994, he had established the Nelson Mandela Children's Fund, a grantmaking body aimed at uplifting the lives of disadvantaged children, and in 2003 he was to establish the Mandela Rhodes Foundation, an NGO aimed at promoting good leadership in Africa through a postgraduate scholarship programme. Mandela had conceptualised the three as ssister legacy organisations،. By 2004, the NMF had grown substantially, with a staff complement of well over 30 people, an annual operating budget of over 6 million USD, and a range of line functions fashioned around projects, campaigns and causes dear to Mandela's heart. The NMF took on anything for which Mandela could raise funds and which did not encroach on the work of the other two sister organisations. Major focus areas were education (from building schools to researching the special challenges of education in rural South
Africa), HIV/AIDS (from advocacy work to grantmaking in support of research), speace and reconciliation` (from supporting the peace process in Burundi to researching democratisation in Africa) and intellectual property (specifically Mandela's, with a strong focus on policing use of his name and image).

In June 2004, Mandela called a press conference at the NMF, at which he announced that he would be stepping away from public life. Privately, he signalled to the NMF's Board of Trustees and chief executive that he would no longer be involved in either determining NMF priorities or fundraising for its projects. In practice, it took him another 6 years to fully implement this statement of intent, but his intervention forced the NMF for the first time to contemplate the unthinkable - what would be its mandate, its role and its sustainability model with Mandela gone? By 2006, in consultation with institutional and other stakeholders, it had decided to convert the organisation into a >Centre of Memory and Dialogue` and to scale down Mandela's personal office progressively. In November of that year the Board of Trustees adopted a 5-year transition plan 
with the completion targeted for February 2012. ${ }^{1}$ This article examines research work done in support of both developing the transition plan and implementing it in the period 2004-2012. It traces the organisation's journey from post-presidential office to human rights-oriented NGO undertaking work in the memory-dialogue nexus, focusing in particular on four research projects central to the reimagining of the organisation's purpose and designed to inform and shape fundamentally the NMF's organizational development change management process. It describes the organisation's use of an action research approach. The four projects scrutinised are: an investigation on the smemory for justice tradition in South Africa and its possible institutional application at the NMF; a global benchmarking study of cognate institutions; a study of dialogue as an element of Mandela's legacy; and a marketing and branding survey. The article begins with a tracing of relevant historical and archival contexts and concludes with an assessment of the organisation's change management process and the efficacy of the organisational research agenda.

\section{Contexts}

Mandela typified his life as a long walk to freedom from the oppression of colonialism and apartheid. The latter, a system of rule implemented formally in South Africa between 1948 and 1994, has been described, most useful, as a form of racial capitalism in which racial differences were formalised and pervasive socially, and in which a society was characterised by a powerful racially defined schism. Among the world's racial orders, South Africa was unique in its rigidity and its oppressiveness. It was declared by the United Nations to be a crime against humanity.

The apartheid regime was not overthrown. The revolution fought for by the liberation movements over nearly three decades did not happen. Instead, between 1990 and 1994, the apartheid government and its political allies negotiated a transition to democracy with the opponents of apartheid. In February 1990, the African National Congress and numerous other oppositional organisations were unbanned, and Mandela was released from prison. This inaugurated democratic election in April 1994. Although the African National Congress won a sweeping victory in that election, it would manage the first 5 years of democracy-building through a Government of National Unity. Crucial to the success of this process was the efficacy of the major players on the ideological terrain in shaping a new national identity. This identity cohered around the notion of unity in diversity and the finding of reconciliation through confronting of oppressive pasts. Its most powerful symbolic embodiment was in the person Nelson Mandela. The nature of the transition to democracy meant that there would be no dramatic dismantling of the apartheid system. Rather, the new system would be built out of the old through processes of transformation.

The first post-apartheid government adopted three interlinked and overlapping strategies for coming to terms with the past: nation building, through the deployment of symbols and metanarratives; the putting in place of special instruments to effect redress and reparation for past injustice; and the longer-term restructuring of the state and the economy to ensure the sharing of wealth and the improvement of equal access to opportunity. The special instruments were wide ranging, from a land restitution process to special pensions for those who contributed to the struggles against apartheid, from a black economic empowerment programme to employment equity policies and strategies. But undoubtedly the centrepiece was the Truth and Reconciliation Commission (TRC), the key mechanism for confronting the past and the one around which the other instruments were constellated. Established in 1995, the TRC delivered its main report to Mandela in 1998 and concluded its business in 2003.

The apartheid era saw the emergence of explicit and reflective use of archive as activism. ${ }^{2}$ In the post1976 apartheid endgame, a tradition and a praxis of smemory for justice became a prominent part of the struggles for liberation, finding expression in struggle performance and other arts, alternative publishing, oral history projects and the counter-archiving endeavour of projects such as the South African History Archive (SAHA), the International Defence and Aid Fund and the Popular History Trust. As elaborated on later in this article, the four key assumptions that informed the 
tradition were as follows: the work of archive is justice; impartiality is a chimera; creating space for the voices and narratives repressed or silenced by apartheid is an ethical imperative; as is countering the dominant metanarratives of the regime and building new ones.

The 1990s saw the apogee of memory for justice as it moved from being a weapon of struggle to being a primary instrument of power in post-apartheid South Africa. There was a flourishing of new archival institutions and projects. The TRC itself could be described as fundamentally an archival intervention. ${ }^{3}$ Resourcing, international and local, was bountiful. The transformation of the country's memory sectors, particularly institutions of the state, enjoyed political support, popular attention and considerable engagement by civil society. Organisations such as SAHA collaborated closely with the National Archives. Archival activism grew in fertile soil. In addition, yet the period also saw what we would call a congealing of energy. Too much of the memory work was superficial, buttressing the new dominant narratives and excluding others. Too much of the political support was about utility rather than principle. Furthermore, too many initiatives were unsustainable.

In the 2000s - what is often called the postMandela era - many of the 1990s archive projects lost energy, became moribund or disappeared altogether. Transformative energies in institutions of the state ran into the sand. Global funding environments became less plentiful. The political will to underpin activist agendas evaporated. Organisations such as SAHA increasingly found themselves in conflictual relationships with the state. Especially after Jacob Zuma ascended to the presidency (in 2009), the National Archives came to regard structures of civil society (such as the SAHA and the NMF) as sthe enemy،. At the same time, the archival activism found new sources of energy and new modes of expression. Continuing struggles for justice attracted funding with an appetite for the archive. Some archival projects were able to reimagine themselves and thrive in changing contexts - SAHA, for instance, was established in the $1980 \mathrm{~s}$ as an underground counter-archive, emerged in the 1990s as part of the post-apartheid memory wave, and in the early 2000s transmogrified into Freedom of Information NGO with robust archival,
This was the context within which the NMF embraced archival activism. It is not an accident that both authors of this article were recruited by the NMF from SAHA. Nor that another two NMF staffers were recruited from SAHA, one of whom rose to the position of chief executive in 2013.

\section{Institutional Processes}

What could be called the NMF's Centre of Memory and Dialogue process started (as a dedicated, systematic endeavour) in the early months of 2004, when one of the authors of this article (Verne Harris) was asked by the NMF to undertake a 12-month feasibility study for what was then called a Nelson Mandela Centre of Memory and Commemoration. At this juncture, the Centre was being conceived of as a special project within the broader medley of NMF functions and structures. It took time to arrange a secondment for Verne Harris from his organisation, SAHA, so that it was the beginning of June before he could take up the brief. In small archival and recordkeeping projects which Verne Harris had undertaken for the NMF in the period 2001-2003, it had become clear that Nelson Mandela's private papers, his office records and the information resources of the NMF together constituted an invaluable archival resource. Initial discussions had considered presidential library and other conventional archival models, but by 2004 there was a consensus that the archive should be mobilised in support of social justice work.

Verne Harris's first day at the NMF was also the day that Nelson Mandela called the press conference mentioned earlier. This was to change the landscape dramatically. NMF management decided to pre-empt the feasibility study, and on 21 September 2004, Mandela publicly launched the Centre as an NMF permanent project. Two of the then-nascent feasibility study's research elements were identified for continuation: an investigation of the smemory for justice tradition in South Africa; and a global benchmarking study of cognate institutions. The former was initiated in late 2004 and is still ongoing, although it was concentrated in the period 2005-2009 for purposes of institutional transition. Planning for the latter began in 2005, and the project was completed in September 2006. 
Perhaps not surprisingly, soon circumstances again shifted the process's scope and focus. By the end of the first quarter of 2006, the NMF's Board of Trustees had decided in principle that the Centre (by now renamed the Nelson Mandela Centre of Memory) should be turned into what it called sthe core business of the organisation, subject to the approval of a 5-year transition plan. An organisational development consultant was commissioned to work with Centre's team members and NMF senior management to develop the transition plan. This is the point at which action research was first engaged as an approach - one capable of absorbing current research endeavour into the planning exercise and framing continuing research envisaged for the transition period. The plan was completed in September 2006 and adopted by the Board in November. ${ }^{4}$ Its key elements were:

- A new mission statement for the organisation: "The Nelson Mandela Foundation, through its Nelson Mandela Centre of Memory, contributes to the making of a just society by promoting the vision and work of its Founder and convening dialogue around critical social issues."

- A phased exit from all projects, programmes and campaigns not aligned with the mission, and a phased closing down of Mandela's personal office.

- Development of a new institutional organogram around four-line functions: records and documentation, research and analysis, dialogue and public programming.

- A substantial phased downsizing of both the staff establishment and operating budgets.

Implementation of the transition plan began under a new chief executive in January 2007. By March of that year, the Centre had already been renamed the Nelson Mandela Centre of Memory and Dialogue, and the proposed organogram reconstellated around twoline functions - memory and dialogue. What became the dialogue programme was quickly put in place, while a study of dialogue as an element of Mandela's legacy in relation to the memory-dialogue nexus was fast-tracked. This research project unfolded through 2007. Its findings, together with assessment of the dialogue work undertaken in the period 2007-2010, led integrate dialogue and memory work both conceptually and organisationally.

In 2009, a marketing and branding survey was undertaken to evaluate public perceptions of the NMF and of sthe Centre Centre moving forward, and inform a comprehensive rebranding exercise. The research findings of this project flowed directly into the final phases of the institutional transition. Also in 2009, the Board of Trustees restated the NMF trust deed to incorporate the new mandate into the organisation's overarching purpose. The latter remained "promoting and developing the cause of peace, human rights and democracy«. But two new elements were added to the explication:

- »the creation, promotion, establishment, protection and preservation of a centre of memory of the Founder which contains an archive of the life and times and the works and writings of the Founder

- convening dialogue around critical social issues including in particular issues regarding human rights and democracy in order to contribute to a just society."

Memory and dialogue, side by side, posing at best a possibility of nexus.

In August 2011, the Board of Trustees:

- Accepted a proposal to complete the closure of Mandela's personal office in February 2012.

- Adopted a new organisational structure built around two-line functions - content development and content delivery.

- Adopted the following new vision and mission statements: the vision is "a society which remembers its pasts, listens to all its voices, and pursues social justice" and the mission is "to contribute to the making of a just society by keeping alive the legacy of Nelson Mandela, providing an integrated public information resource on his life and times, and by convening dialogue around critical social issues."

- Approved a re-branding of the organisation as the Nelson Mandela Centre of Memory and its final retooling as a leaner human rights-oriented NGO, to be completed by February 2012.

- Authorised the reduction of the staff establishment to 21 posts and the annual operating budget to just over 4 million USD. 
What had been conceptualised as a shift from NMF to Centre of Memory (and Dialogue) and from a personcentred mandate to a purpose-centred one, gathered momentum as Mandela finally stepped away from public life in 2010 and his personal office at the NMF was closed at the end of 2011. However, growing evidence of the significant recognition and goodwill carried by the NMF brand led the Board of Trustees in 2013 to decide not to replace one brand with another. This was a classic instance of the messiness of processes informed by action research, with initial plans and trajectories routinely changing in response to findings. ${ }^{5}$

The organisation would remain the NMF and the Centre of Memory would instead become the name and the identity of the NMF's physical property in Houghton, Johannesburg. A fundamental refurbishment of this property had been initiated in 2011 to make it an appropriate home for an organisation doing work in the memory-dialogue nexus. The re-imagined physical home was shaped around customised archival preservation areas, permanent and temporary exhibition infrastructure, a public reading-room, and dialogue and conferencing spaces. The NMF's Centre of Memory was launched as a multipurpose public facility in November 2013 just weeks before Mandela passed away.

What we have described is an 8-year period of intense and ever-shifting change management. These processes are always exhausting, if not traumatic, for organisations and individuals. Allowing them to continue as long as the NMF did posed a fundamental and defining challenge to its research agenda. Subsidiary challenges were multiple. The 2004 decision to pre-empt a feasibility study had consequences - it might have delivered a very different framing model for what became the Centre of Memory; it certainly would have ensured better planning and systematic endeavour; and it might also have positioned the NMF to avoid at least some of the false starts made during the next 8 years. ${ }^{6}$ Mandela's protracted phased withdrawal from public life unfolded in contexts within which he remained under intense pressure to intervene politically, both locally and internationally. The NMF had to manage the consequent tensions and frequently prioritise the spersonal over the sinstitutional change. management processes left the organisation in early 2006, and for a year an acting chief executive held the processes together. This, combined with the impact of a reduction (by over a half) in the size of the Board of Trustees in 2007, introduced a period of instability at the highest level of strategic direction. Staff reductions, relatively high staff turnover in certain areas, and the absence of dedicated in-house research and analysis as well as monitoring and evaluation capacity, introduced instability at other levels. Mandela's withdrawal meant the loss of the NMF's primary fundraising resource, so that sustainability pressures grew substantially and sapped institutional energy at the time it was needed the most. What we have described, arguably, is an optimal environment for action research.

\section{Action Research}

Action research is at once an approach, a strategy and methodology. It can be implemented systematically, selectively or on an ad hoc basis. It was first recognised in the work of Kurt Lewin, who in the wake of the Second World War conducted a form of action research that sought to address urgent social issues such as segregation, discrimination and assimilation. ${ }^{7}$ In the best of circumstances, action research is fluid and open. However, more often than not it entails embracing "messiness, uncertainties, instabilities and value conflicts «. ${ }^{8}$ This is because even well-planned projects "are messy entities: timescales slip, personnel change and research tools seldom elicit exactly the answers we intend «. ${ }^{9}$ NMF's change management process was a messy one. Action research has been understood and defined in different ways. In the view of the authors, ${ }^{10}$ it possesses four primary defining attributes:

- While knowledge generation is an important objective, the primary objective is to both inform and impact on action. According to Williamson, ${ }^{11}$ the intention of action research is to end "the dislocation of research from practice«. For Rolfe, ${ }^{12}$ the research must be aimed at bringing about »direct improvement in the situation being researched«. For Stringer, ${ }^{13}$ such research "focuses on specific situations and localised solutions«. 
- It at once concentrates on situations within which the practitioner-researcher is embedded and on practical problems confronting the practitionerresearcher in those situations. In other words, the practitioner-researcher is not, and cannot be, detached from the process. She is actively involved in it and must factor that involvement into the research. She must be self-reflective, own her complicity, and disclose it explicitly. As Rolfe argues, "for the practitioner-researcher, whose aim is to integrate research in her everyday practice, a reflexive approach to action research is required «. ${ }^{14}$

- It carries with it commitment to a continuing process. For both Lisle ${ }^{15}$ and Williamson, it carries an implicit and recurring sequence: plan-act-observe-reflectrevise plan-act and so on. Oosthuizen ${ }^{16}$ asserts that it is cyclical in nature, with latter cycles being used "to challenge, support and refine insights and results from previous cycles«.

It encourages and supports participative and collaborative forms of data collection. In the formulation of Morton-Cooper, ${ }^{17}$ it is based on "action, and on participative and collaborative forms of data collection which can be used to change our ways of working and seeing the world".

The use of an action research approach by the NMF in the period 2004-2012 was neither a formal nor systematic one. It was done more or less reflexly in response to contexts of rapid institutional change, instability, messiness and demands for decisive action (১internally، and sexternally`). Action research thinking was first introduced to the change management process only in 2006. In addition, while individuals involved in shaping the process from then on were influenced by action research methodologies, it was only much later, after 2012, that action research was adopted as the institutional approach،. In retrospect, the key influence drawing the NMF to its use was the nature of the research warrant informing the process. Three primary loci of authority for this warrant can be identified:

- Nelson Mandela. Of particular importance here are his legacies of commitment to social justice, insistence on individuals taking responsibility for their own liberation and that of the collectivities they find themselves in, the practice of collective decision-making, and belief in dialogical knowledge construction and problem-solving. As Avison et al. argue, action research should unfold "within a mutually acceptable ethical framework «. ${ }^{18}$ Mandela provided a particularly robust one.

- The NMF's Board of Trustees. The Board had set the specific research goals within an overarching imperative for institutional change management, a commitment to the concept of smemory for justice`, and a requirement that the two Mandela's sister legacy organisations and other institutional stakeholders participate meaningfully in the process. This determined regular updates to and consultations with the sister organisations, a steering committee put in place for the Centre of Memory project in the period 2004-2006, a network of 40 >memory institutions with a direct stake in the Centre's work, a broader network of 80 South African-based >memory institutions and the Mandela family.

- NMF funders. From 2006, the bulk of funding grants secured by the NMF were designated specifically for work in the memory-dialogue nexus, and came with conditions for research-based transition initiatives, for the meeting of (researched) beneficiary needs, and for action resulting in measurable impact.

\section{Memory for Justice Research Project}

When Nelson Mandela inaugurated the Centre of Memory project publicly on 21 September 2004, he indicated that the Centre's most important shaping influence should be the call of justice:

Today we are launching the Nelson Mandela Centre of Memory Project. We want it to be part of what we have called the processes of restoration and reconciliation [...] We want it to work closely with the many other institutions which make up the South African archival system. And, most importantly, we want it to dedicate itself to the recovery of memories and stories suppressed by power. That is the call of justice. The call which must be the project's most important shaping influence. ${ }^{19}$ 
In March of the following year, he repeated this sentiment when speaking at the launch of the Centre's first exhibition in the foyer of the Constitutional Court. This constituted a powerful public marking of a determination that the Centre should find an institutional expression for the concept of >memory for justice and position itself in relation to South Africa's struggle-era smemory for justice, tradition. Four tenets perhaps best define that tradition, which had a long provenance and multiple tributaries but which coalesced strongly during the apartheid era's post-1976 endgame:

- The work of memory is an integral part of the struggles against apartheid oppression.

- The memory practitioner is not an impartial custodian - rather, she is a memory activist, either for or against the oppressive system.

- Creating space for the voices and the narratives repressed or silenced by apartheid is an ethical imperative.

- As is countering the dominant metanarratives of the regime and building new ones. ${ }^{20}$

Interrogation of the tradition, exploration of what it might mean in post-apartheid contexts, and investigation of how the Centre might embrace and express the concept underpinning it had been identified as key lines of enquiry for the commissioned feasibility study mentioned earlier. While the study was aborted, as explained earlier, a mandate was given to the Centre's team to pursue systematically a research focus aimed at supporting the enquiry. This focus remains in place and has been undertaken across a wide range of research platforms: scholarly research by individual team members, issuing in conference papers, journal articles, chapter contributions to books and a book dedicated to the subject; ${ }^{21}$ research commissioned around specific research questions on a consultancy basis; formal and informal consultations with stakeholders; advocacy-directed dialogue forums and community-based dialogues. However, the research project in its reflexive orientation toward institutional change management was framed around three primary dialogue interventions, in 2005, 2007 and 2009. Each was designed to channel knowledge and experience into the institutional transition process, each was provided with a collaborative focus group as the primary output mechanism, and the three were built progressively as a series (with outputs being fashioned into inputs for what followed).

The first in the series, the colloquium "Memory for Justice«, was convened by the NMF on 18 August 2005 under the guidance of a focus group comprising the head of the Centre's team, a professor from the University of the Western Cape and two international participants. As a research technique, the focus group is used to study an issue or a small set of issues in a carefully structured dialogical setting. ${ }^{22}$ The literature suggests that this type of setting works best with between 6 and 12 participants. The smaller group agreed to as best suited to the specific output requirements for the colloquium. The group began its work by providing the initial provocation to the invited speakers and delegates representing over 30 memory institutions in South Africa. The brief was to historicise the concept of 'memory for justice explore its modes of institutional expression in the present. The colloquium ended with a review session led by one of the focus group members. Subsequently, the group generated a draft report summarising the key propositions to emerge from the dialogue and distributed it to delegates for comment. A revised final report ${ }^{23}$ was then published on the NMF website and disseminated through institutional channels. This report was absorbed by the NMF institutional change management process and shaped indelibly the 5-year transition plan adopted by the Board of Trustees the following year.

One of the key findings of the first dialogue in this series was that South Africa's post-apartheid national archival system was in deep trouble. This became the focus for the second in the series of interventions, a more or less conventional conference entitled »National System, Public Interest « framed by a collaborative focus group both providing inputs and harnessing outputs. The conference was co-convened on 23 and 24 April 2007 by the NMF, the National Archives and the University of the Witwatersrand (Wits). The focus group comprised two team members of the Centre, two National Archives representatives and a professor at Wits. It determined the initial provocation to invitees, commissioned speakers, chaired a review session at the end of proceedings and drafted a report subjected to review by the institutional partners. This report was 
published by the NMF and submitted to the Minister of Arts and Culture. ${ }^{24}$ The Minister referred it to the National Archives Commission, which invited the focus group to present it at a Commission meeting. It was also absorbed by the NMF institutional change management process as a demonstration of collaborative researchbased advocacy in the memory-dialogue nexus and an indication of how South Africa's >memory for justicer tradition might still be living-energy capable of meaningful expression in institutional spaces. It also became a key resource for the process in scoping the wider environment - institutional, archival and political - in which the Centre was being positioned. More directly, one of the report's recommendations issued in a joint NMF-University of Cape Town project, the Archival Platform (launched in 2009), the primary aims of which were to break down disciplinary and other boundaries in the memory sector and to harness cross-sectoral knowledge and experience in support of social justice initiatives.

Lessons learned from the 2007 intervention became the basis for a carefully structured dialogue forum on the theme »Reconciliation and the work of memory in post-apartheid South Africa", co-convened by the NMF and SAHA on 2 and 3 April 2009. Again, a collaborative focus group, comprising representatives from the NMF, SAHA, the South African Human Rights Commission and the University of Cape Town, was mandated to set the agenda and harvest the outputs. The group's initiatory provocation was in the form of two questions: could it be that South Africa's post-apartheid memory work has been too superficial and that the really difficult memory work remains to be done? Four sessions were designed, each with a commissioned speaker and respondent, to explore the questions along what the group had determined were fundamental faultlines in South African society: the law, race, rights and power. A report was commissioned from one of the group's members, which was subjected to review by a second, broader focus group, and then published through joint conference papers and as a chapter in a book..$^{25}$ The report became the basis for designing a 2011 dialogue forum exploring the major impediments to accessing information about South Africa's pasts. Crucially from an institutional perspective, the report played a pivotal role in convincing the NMF change management process that setting up smemory، and rdialoguer as parallel functions in the Centre was undesirable. By early 2010, NMF management was convinced that memory and dialogue belonged together both conceptually and functionally.

Arguably of fundamental significance was that the focus group responsible for the third dialogue intervention married it to a workshop bringing together South Africans who had been involved in the South African TRC and Kenyans - representing both state and civil society structures - participating in the formation of that country's Truth, Reconciliation and Justice Commission. All workshop delegates first attended the dialogue forum, then, under the aegis of the Rosa Luxemburg Foundation and the Goethe Institute, on 4 April 2009 engaged in a dialogue on lessons learned from the South African experience and their possible application in the contexts of Kenya. One of the focus group members (Shadrack Katuu) was commissioned by the Goethe Institute to draft a report, which was published after review by the group. ${ }^{26}$ For the NMF change management process, this was another demonstration of a model for addressing critical social issues within a memory-dialogue nexus framed by a social justice imperative.

The memory for justice project in this period demonstrated the considerable convening power of the NMF and in particular its capacity to draw structures of the state into processes involving civil society and the private sector. In a period of growing alienation, for example, between the National Archives and the civil society archival sector, engagement by the National Archives with an NMF project was significant. However, the project had its shortcomings. Community-level participation was minimal. The analysis focused on content at the expense of the process, memory work at the expense of dialogue methodology. Standard monitoring and evaluation exercises were not implemented. And very few lessons were harvested for the NMF's dialogue programming.

\section{Benchmarking Study of Cognate Institutions}

The initial design of the Centre of Memory feasibility study mentioned earlier, commissioned in 2004, had 
included a survey of memory institutions in South Africa, with a special focus on those having a stake in the legacy of Nelson Mandela. While the study was aborted, as explained earlier, the need for such a survey was recognised and incorporated into change management planning over the next 18 months. By late 2005, the scope of the planned survey had been expanded to have a global reach and to incorporate institutions founded by or in the name of a prominent individual. The survey was undertaken by two University of Toronto interns at the NMF in the period May-July 2006, and became the first phase of what was later called the "Benchmarking study of cognate institutions «. Phase 2 drew on the data generated in phase 1 , involved more intensive research of a selection of institutions studied in phase 1 , and was undertaken by a commissioned research consultant with a brief to prepare the research findings for incorporation into the 5-year institutional transition plan being prepared for submission to the Board of Trustees in November 2006. Phase 2 unfolded in the period July-September 2006.

Phase 1 aimed to use desktop research to accumulate data on the identified institutions in six categories: legal status, mandate, governance, funding, resources and internal structure. Included in the brief was the need for a wide geographical spread and a focus on institutions with a strong legacy dimension in their mandates. Given the scope and purpose of the exercise, the research design relied on descriptive survey techniques. In descriptive surveys, the primary purpose is to »describe a particular phenomenon: its current situations, its properties and conditions « based on extensive data collection, data arrangement and trend identification. ${ }^{27}$ With the research questions privileging breadth rather than depth, purposive sampling was selected as the main data collection technique. This technique is a category of non-probability sampling, described by Henry as »having the distinguishing characteristic that subjective judgements play a role in the selection of the sample «. ${ }^{28}$ It relies on the researcher having the required expertise and experience and using the design criteria to identify subjects most relevant to the study. ${ }^{29}$ Overseen by the team members of Centre, the two interns, both masters students in information studies, identified 73 institutions for inclusion and proceeded to generate a report comprising institutional profiles of each across the six data categories defined in the research brief.

A second phase for the project was decided on after phase 1 had commenced. A focus group comprising an organisational development consultant and Centre team members was assembled to assess the findings of phase 1, prepare the research brief for phase 2 and absorb the phase 2 findings for injection into the 5-year institutional transition plan. The brief to the research consultant was: to select between 5 and 10 institutions covered in phase 1 for more intensive study; to base the selection on these institutions' alignment with the Centre's goals and positioning in relation to the memory-dialogue nexus; to generate detailed data accumulations for each institution using the same six themes - legal status, mandate, governance, funding, resources and internal structure - deployed for phase 1 ; and to distil the key lessons to be learned by the NMF from these institutions' experience.

Given the imperative in phase 2 to secure answers to show? works best in specific contexts, the research design adopted explanatory survey techniques. In explanatory surveys, description is used as a basis to reach further in an attempt "to establish why things might be the way they are.$^{30}$ Such surveys, in the view of Tanner, explore the "interrelationships of variables and likely causal links between them «. ${ }^{31}$ Using the criteria set by the focus group, the research consultant identified eight institutions for further study - the Carter Center, Desmond Tutu Peace Centre, Franklin Roosevelt Presidential Library, Gandhi Foundation, Helen Suzman Foundation, John Kennedy Presidential Library, the King Center and the Clinton Foundation. More intense desktop research on each was followed by interviews with one representative from each institution. This data collection technique was employed given the tight time constraints for the project, and the technique's utility in accessing privileged information, probing opinions and exploring experience in depth. ${ }^{32}$ Semi-structured interviews were conducted, ${ }^{33}$ allowing for both predetermined questions crafted to meet the NMF's information needs and elaboration by interviewees leading to improvised follow-up questions. A set of 38 predetermined questions (organised within the six research themes) was agreed on by the focus group and 
the research consultant. Data were then assembled in a comprehensive report containing both data and tentative findings sections. ${ }^{34}$ The focus group interrogated the report in meetings with the research consultant until a final set of findings was developed collaboratively. The main lessons learned were as follows:

- Successful promotion of a legacy hinges not on the use of a name, but purposeful action having an impact on society.

- Mandates sustainable over time tend to be purpose centred rather than person centred.

- A sustainability plan not dependent on involvement by the institutional founder is essential.

- Memory work is difficult to sustain without endowment or state support. At the same time, state support for memory work with a social justice dimension is problematic.

- Blurring of boundaries between institutional spaces and those of the founder's family invites complexity and incurs many risks.

- Absolute clarity must be secured in relation to ownership of the founder's memory resources and broader intellectual property.

- Liaison and joint endeavour with sister and other stakeholder institutions are desirable, but the institution's mandate must be distinctive.

- Beneficiary categories and target audiences must be clearly defined.

- Good governance is absolutely critical for credibility.

The findings were then woven into the draft 5-year institutional transition plan, ${ }^{35}$ which was given to the research consultant for comment on the appropriateness of the interpretation and application of the findings. It would not be an exaggeration to say that the benchmarking project shaped the final transition plan fundamentally.

Rather than being part of a wide-ranging and more or less open-ended feasibility study, the benchmarking project focused on learning lessons from cognate institutions within a predetermined conceptual and strategic frame. It was a discrete intervention designed to meet the urgent immediate needs of the NMF at a particular juncture in its history. The absence of dedicated in-house research and analysis capacity at that juncture diminished the NMF's ability both to absorb its findings effectively and to secure traction for its recommendations. Nonetheless, the project became the platform for continuing comparative research aimed at determining best practice and learning lessons from cognate institutions. For instance, regarding the development of a web platform for the NMF known as the Mandela Portal, the benchmarking project provided key insights from the work of peer institutions. ${ }^{36}$ In this and other similar instances, the research has ranged from desktop to formal research-oriented visits to other institutions, from interviews to visits to the NMF by either experts in particular fields or representatives of specific cognate institutions. This continuing benchmarking has been fed into and shaped the implementation of the transition plan.

\section{Dialogue Study}

As is outlined in an earlier section of this article, during the first quarter of 2007 the NMF's dialogue function was elevated to one of two core line functions and a programme put in place to support it. Simultaneously, a dedicated research project was authorised to enable the NMF to deepen its understanding of dialogue in relation to both Nelson Mandela's legacy and the memorydialogue nexus, and to chart a development strategy for the new programme. The project built directly on a dialogue mapping exercise undertaken in 2005 and 2006 by the NMF's organisational development consultant. Working with three dialogue practitioners, the consultant had provided an overview of what were called ıtools for dialogue` (approaches, models and methodologies) and assessed their strengths and weaknesses. The report had made no attempt to apply its analysis directly to NMF contexts. In 2008, the authors turned the report into a book. ${ }^{37}$

Because of the high-level liaison and access to confidential information that would be involved in the dialogue research project, it was decided to set stringent criteria for selection of a research partner. A tender process resulted in a consortium, Resolve Group-TraceConverse (RTC), winning the competition and being given the mandate to complete its work by December 2007. The brief to RTC was to: define Mandela's legacy in relation to dialogue, explore the conceptual connections 
between memory and dialogue, and recommend how the NMF should best shape, structure and implement its dialogue function.

RTC's research design was structured around four key research questions: ${ }^{38}$

- Emotion: „What does Mandela mean to me?«

- Biography: „What does Mandela's life tell us about dialogue and his approach to it? What values and qualities does he embody?«

- Legacy: "How will future generations know that Mandela embodies the above values and qualities, and experience them for themselves? «

- Institution: "How should the NMF root these values in its own practice and in society through dialogue programming?«

Their research was undertaken in three phases: a preliminary phase comprising consultations with senior NMF staff, desktop research and privileged access to Mandela's private papers; a phase of what they styled >deep interviews`; and a final phase of focus groups.

The preliminary phase enabled RTC to understand the institutional and broader contexts within which the project would be operating, develop hypotheses in relation to the key research questions, and identify appropriate interviewees and participants for phases 2 and 3. Purposive sampling determined the subjects for deep interviews. The primary criterion was a longstanding relationship with Mandela, whether as a family member, friend, political comrade, associate, political adversary, fellow-prisoner or interlocutor. A total of 23 individuals were interviewed, all prominent in public life and many of great political seniority. Given their stature, and the need for deep interpretive probing, the technique used was the semi-structured interview. Thirteen predetermined questions developed from the five key research questions were used as a springboard for sometimes wide-ranging reflection and enquiry.

The final phase involved six focus groups determined by the phases 2 and 3 research to represent key stakeholder groupings. Use of the focus group technique for the project was informed by the subject of the enquiry - dialogue - and a need to provide a balance to the deep one-on-one interviews. It also promised to yield useful insight into ssector perspectives. The six groups ranged in size from 3 to
25 participants and represented Eastern Cape (where Mandela was born) senior traditional leaders, Eastern Cape junior traditional leaders, public intellectuals, youth and students, senior NMF staff and junior NMF staff.

RTC submitted its report on December 2007. Its findings were wide-ranging, but four were of particular significance for the NMF:

- Dialogue is a fundamental element of Mandela's legacy.

- Dialogue is a vital instrument for addressing critical social issues in the contexts of post-apartheid South Africa.

- There is "an organic relationship between ımemory and `dialogue «.«39

- A wide range of dialogue models and methodologies, each with advantages and disadvantages, could be considered for programme functionality at the NMF.

The report was immediately submitted to an NMF focus group, comprising former trustees of the organisation, for consideration. Widely divergent views on the report were expressed, considerable disquiet surfaced in relation to the report's propositions on what it termed Mandela's ıvalues and qualities`, and no consensus emerged around the relative merits of the dialogue models and methodologies. This response was mirrored by a later Board of Trustees' response.

Without Board endorsement, the dialogue study carried no formal authority within the NMF. It had its weaknesses, notably in terms of its limited range of focus groups and its failure to engage robustly with the very concept of dialogue. The NMF's own lack of dedicated in-house research and analysis capacity constrained its ability to engage critically with the study. Not surprisingly then, the impact of the study on the institutional change management process was limited. Centre team members were influenced differentially, and while certain elements of the study were engaged by NMF senior management, others were discarded. But the study's influence can be discerned in the perspective on dialogue which emerged in the NMF over the following years - a perspective honed by hard experience gathered by both the dialogue and memory programmes across a range of platforms, from community dialogues addressing issues like 
HIV/AIDS and xenophobia to verbal presentations on draft legislation in Parliament, from negotiations with state representatives behind closed doors to media conferences on the state of Mandela's health. Six propositions define the perspective:

- Memory is dialogue.

- Memory should always be negotiated collectively.

- The most effective vehicle for sharing a memory, for growing it, and for engaging it in the promotion of justice is dialogue.

- Dialogue demands a sustained negotiation, by all the stakeholders in a particular social issue, focused on finding sustainable solutions to problems, committed to building futures with pasts, in an environment hospitable to a hearing of sthe other .

- The unique strength of the NMF is its capacity to bring to the table people who do not want to listen to one another and to provide a space safe enough for people to consider saying the unsayable.

- The objectives of the NMF are best served, and its strengths are best used through an integration of the memory and dialogue functions.

And the study influenced the decision, taken in 2010 and implemented the following year, to collapse the memory and dialogue functions and structures and to reorganise the NMF's core functions around content development and content delivery. At the end of the 5-year transition plan, the revised institutional vision was for dialogue to shape memory construction, memory to shape dialogue interventions, and dialogue to enrich and energise memory resourcing - organic relationships, in other words, energising social justice action and determining appropriate models and methodologies through a dialogical engagement with the specificities of time, place and voice.

\section{Marketing and Branding Survey}

From the inception of the institutional change management process, the NMF had relative clarity on the communications, marketing and branding challenges facing the organisation. A chapter of the 5-year institutional transition plan was dedicated to "external communication and marketing «. ${ }^{40}$ The absence of an organisational definition of communication and marketing objectives was noted, and the need for implementation of state-of-the-art communication tools and tactics was recommended. Implicit was recognition of an imperative to prioritise content delivery and rebranding. In terms of public perceptions of the NMF, the plan was explicit: ${ }^{41}$

- $\quad$ The NMF is perceived as being merely the Founder's office."

- „The NMF is occasionally perceived as a trust for the Mandela family."

- "The complementary mandates of the Mandela charities have not been communicated. The NMF is often mistaken for the Nelson Mandela Children's Fund and vice versa."

This analysis was based on qualitative impressionistic internal research. By 2009, the transition process had progressed far enough to test the analysis against the results of externally driven hard quantitative research. In April 2009, Grey South Africa was commissioned to undertake such research. Grey used TNS Research Surveys for the survey work, and presented its analysis of the results to NMF management in May. ${ }^{42}$

The research design employed by TNS was based on the NMF brief to:

- Determine awareness of the NMF.

- Ascertain what people think the NMF does (without prompting).

- Ascertain what activities the NMF is involved in (prompted, including functions in the memorydialogue nexus).

- Ascertain which activities people feel it would be good for the NMF to be involved in.

TNS undertook a representative sampling of urbanbased South Africans. Positioned within a descriptive survey framework, the exercise deployed structured interviews to measure respondent views on questions crafted in terms of the research brief. A total of 2000 people living in seven urban centres were interviewed.

Over $60 \%$ of the respondents were aware of the NMF, although positive responses were concentrated in more affluent areas and strata. Other results confirmed the transition plan's assessment. The NMF was perceived 
as founder-driven and focused on uplifting the poor and disadvantaged. High levels of confusion between the NMF and the Children's Fund were apparent. There were low levels (10\%-20\%) of awareness of and support for activities in the memory-dialogue nexus. The highest levels of support (20\%-44\%) were for activities perceived as contributing to the upliftment of the poor and disadvantaged.

These findings were sobering and would have been more so if the survey had reached beyond big urban centres into the country's small towns and deep rural areas. They energised the adoption of a robust marketing and re-branding strategy. The first step had already been taken before the survey - at the beginning of 2009, all communication functions had been integrated and a new senior manager had been appointed to drive these functions. By the end of 2011, this manager had been appointed as the head of the newly constituted content delivery programme. A multi-language (South Africa has 11 official languages) delivery capacity was put in place. The institutional website (www.nelsonmandela.org) was revamped, with integrated mobile phone and social media delivery platforms (Katuu et al., 2011). ${ }^{43}$ The Nelson Mandela International Day campaign was launched (2009) as a strategy for enabling grassroots participation in the making and re-making of Mandela's legacy. By 2011, significant national and international footprints had been secured by the campaign. A digitisation project in partnership with Google was launched (2010) to support the web-based delivery of archival content. New emphasis was placed on institutional partnerships aimed at expanding the NMF's footprint, especially in systemically disadvantaged communities in South Africa. By the end of 2011, over 20 such partnerships were in place. A new logo and associated branding instruments were adopted for the Centre of Memory by the Board of Trustees in August 2011. Taking into account the marketing and branding survey's demonstration of significant NMF recognition and goodwill levels, the new brand was a development rather than a complete break from the NMF brand. Of course, as was explained earlier, just a year later the Board backtracked on this as it absorbed the data emerging from research and other forms of engagement, deciding instead to return to the physical home of the institution. This was to result in brand confusion for years afterwards.

\section{Conclusion}

For organisations with secure funding streams and operating in cultures where accountability is not prioritised, there is little incentive to subject their work to continuing research-based scrutiny. For human rights-oriented NGOs dependent on designated donor funding, the incentive is strong but the capacity to support such scrutiny is usually limited and attention distracted by the pressure and urgency at the delivery coalface. This study has described an organisation in the transition from the former category to the latter. A combination of access to relatively generous resourcing and an injection of human rights cultures enabled the NMF to commit to a change management process informed by systematic research-based scrutiny of its work, its internal operations and the environments in which it seeks to make an impact. In practice, the endeavour between 2004 and 2012 was at best more or less systematic. As this study has shown, the goalposts at strategic levels were constantly shifting, many of the interventions were either not part of strategic planning or were adapted to changed circumstances or by factors at tactical levels, and much of the endeavour was more reactive than proactive. Ideal contexts for and appropriate attributes of, it could be argued, action research. Again, it must be stressed that this study has focused on four research projects which:

- were designed to support a reimagining of the organisation's purpose and the re-tooling of its line functions;

- were connected directly and reflexively to the organisational change management process;

- were positioned, either centrally or tangentially, within a memory-dialogue nexus and

- can be positioned within an action research frame.

Numerous other research projects falling outside the ambit of this study were undertaken in the period under review - from functional analysis in support of the restructuring of human resources to a study of website development and use; ${ }^{44}$ from a scoping of 
intellectual property law to an audit of Mandela-related archival materials. These projects, it is argued, played a subordinate role in the NMF's transition. But scrutiny of them might well depict a picture of the transition bearing more evidence of systematic, planned and carefully coordinated endeavour.

One of the aims of this study has been to demonstrate the suitability of an action research approach to the purposes and the contexts of the core research undertaken by the NMF in the period 2004-2012. This explains the considerable attention given to the wider institutional change management process and its contexts. One of the defining characteristics of action research is its engagement with specific situations and commitment to being a catalyst for change in those situations. All four projects detailed in this study were geared to provide an effective institutional change and to positioning the institution to become a more effective change agent in society. While in every instance, >outside` partners were either drawn into the research or commissioned to undertake the research, the endeavour was inside-driven and its outputs channelled either exclusively or significantly into the transformation of the sinsider. The detachment was out of the question. Institutional sself-reflection` was fundamental. Collaborative data collection, of course, is another defining characteristic of action research, and all four projects, to varying degrees, involved in collaboration at this level. In addition, all four projects were, on the one hand, framed within a continuing, open-ended research agenda and, on the other, given openings to either continuing endeavour or followthrough interventions.

The work continues at many levels. While some of the institutional objectives articulated in the 2007-2012 strategic plan were not realised, both the overarching vision and the commitment to research-driven change remain very much in place. The planned institutional name change (from NMF to Centre of Memory) did not take place. The imprint of sperson has proved resilient. The pull of iconic association has made the push towards slean and mean surprisingly difficult. However, Nelson Mandela's 2009 mandate as expressed in the restated Deed of Trust still underpins everything that the NMF does. The 2011 vision and mission statements still inform endeavour. And the four research projects continue to reverberate strongly in the organisation. At the time of writing (2019), >Memory for Justice` is regarded as a work in progress at the NMF. Action research in this area since 2013 has seen the NMF involved in the publication of three major reports - "Memory for Justice«, "State of the Archive" and "Four Decades of Archival Activism in South Africa ${ }^{45}$ Benchmarking, monitoring and evaluation have become routine organisational tools. Significant in-house research and analysis capacity has been secured. And the NMF's practice of dialogue today is rooted in the learnings of the period 2004-2012. The programme supporting this work embraces an action research strategy, is committed to deep reflection, and continues to explore what it means by dialogue and to test the efficacy of work undertaken in the memorydialogue nexus. In 2017, for example, the Board of Trustees adopted internally generated position papers articulating an updated theoretical framing for NMF dialogue work and defining the parameters of NMF activism.

Of course, reflexivity, an attendant and arguably intrinsic flexibility work at different levels. This study has demonstrated the degree to which institutional change management processes both determined and were impacted on by the four research projects. It outlines the messiness of these processes and details the key lessons learned. It also shows a reflexive dimension to the relationships between the projects. Each was positioned in relation to the others in a predetermined pattern, but at the same time projects' outputs in every instance shifted the constellation and influenced the others, whether in terms of timing, framing or adoption of recommendations. Flexibility is also apparent at more conceptual or theoretical levels. An action approach allows for a framing permeable to both the qualitative and the quantitative. In epistemological terms, it resists positivism but values empirical evidence. So that at the levels of design and technique (again, as is demonstrated by this study), a flexible and wide range of tools made available. Ideally suited, this study argues, to the needs and imperatives of the institution which is the subject of this case study during the period 2004-2012. 


\section{Acknowledgements}

The authors cannot claim to be impartial observers of the processes they describe in this study. Verne Harris was involved in the Nelson Mandela Centre of Memory Project from its inception in 2004 and remains a senior staff member at the Nelson Mandela Foundation. Shadrack Katuu was head of information systems at the Nelson Mandela Foundation from 2005 to 2009 and acted as a consultant to the organisation from 2009 to 2010. Both were participants in all the research projects detailed in the study. This lack of detachment could be seen as a weakness, but from an action research perspective, it could be regarded as a strength. Whatever the view of the reader, this fact has been disclosed. Shadrack Katuu is currently a Research Fellow with the Department of Information Sciences, University of South Africa, and Verne Harris is an Adjunct Professor at the Nelson Mandela University. The views expressed in this study are those of the authors and should not be attributed to their institutions. The authors would like to thank Lee Davies, Sello Hatang, Jill Ruby and Sahm Venter for their assistance with the research for this study. 
1 NMF business plan 2007-2011. Internal document, Nelson Mandela Foundation, Johannesburg 2006.

2 In the remainder of this section of the article, we draw heavily on Verne Harris' contribution to the introduction of what became a 2018 report on archival activism in South Africa. See Archival Platform 2018.

3 Verne Harris: Archives and Justice. A South African Perspective, Chicago 2007, pp. 289-304.

4 NMF business plan 2007-2011.

5 Stephen Kemmis / Robin McTaggert: Participatory Action Research. Communicative Action and the Public Sphere, in: Norman K. Denzin / Yvonna S. Lincoln (eds.): The Sage Handbook of Qualitative Research, Thousand Oaks, CA 2005, pp. 559-603, at p. 563.

6 The decision was taken in an attempt to fast-track processes in conditions of significant uncertainty in the wake of Nelson Mandela's public announcement that he would be stepping away from public life and from the NMF. One of the consequences was a more or less improvisational approach which drew heavily on staffers' experiences of the SAHA model. It should be noted that at the time of writing (2019) SAHA is facing severe sustainability challenges and is close to having to terminate its operations.

7 Dorothea Nelson: Participatory Action Research. A Literature Review, University of Calgary 2017, online: https://www.researchgate.net/ publication/321398218 (17. 05. 2019), p. 6.

8 Joanne Evans: Capacities and Complexities. A Reflection on Design Methodologies for Archival and Recordkeeping Research, in: Anne J. Gilliland / Sue McKemmish / Andrew J. Lau (eds.): Research in the Archival Multiverse, Clayton 2017, pp. 659-685, at p. 669.

9 Vivienne Baumfield / Elaine Hall / Kate Wall: Action Research in Education. Learning through Practitioner Enquiry, London 2013, p. 137.

10 Hart and Bond (1995) argue that there are seven defining attributes of action research, see: Frederick Hart / Meg Bond: Action Research for Health and Social Care. A Guide to Practice, Buckingham 1995.

11 Kirsty Williamson: Action Research. Theory and Practice, in: Kirsty Williamson / Graeme Johanson (eds.): Research Methods. Information Systems and Contexts, Cambridge, MA 2018, pp. 209224, at p. 211.

12 Gary Rolfe: Expanding Nursing Knowledge. Understanding and Researching Your Own Practice, Oxford 1998, p. 195.

13 Ernest T. Stringer: Action Research, Thousand Oaks, CA 2007, p. 1.

14 Rolfe: Expanding Nursing Knowledge, p. 195.

15 Angela Mary Lisle: Reflexive Practice. Dialectic Encounter in Psychology and Education, Bloomington 2010.

16 Majola J. H. Oosthuizen: Action Research, in: Kirsty Williamson (ed.): Research Methods for Students, Academics and Professionals. Information Management and Systems, Waga Waga 2002, pp. 159175 , at p. 161.

17 Alison Morton-Cooper: Action Research in Health Care, London 2000, p. 17.

18 David E. Avison et al.: Action Research, in: Communications of the ACM 42/1 (1999), pp. 94-97, at p. 94.

19 A Prisoner in the Garden. Opening Nelson Mandela's Prison Archive, Nelson Mandela Foundation, Johannesburg 2005, p. 98.

20 Verne Harris: Jacques Derrida meets Nelson Mandela. Archival Ethics at the Endgame, in: Archivaria 11/1 (2011), pp. 113-124.

21 Harris: Archives and Justice.

22 Alan Hevner / Samir Chatterjee (eds.): Design Research in Information Systems. Theory and Practice, New York 2010, p. 122.

23 Randall C. Jimerson: Archives Power. Memory, Accountability and Social Justice, Chicago 2009, pp. 365-368.
24 Archives at the crossroads 2007. Open Report to the Minister of Arts and Culture from the Archival Conference sNational System, Public Interest held in April 2007 and co-convened by the National Archives, the Nelson Mandela Foundation and the Constitution of Public Intellectual Life Research Project, Johannesburg 2007, online: https://www.nelsonmandela.org/images/uploads/NMF_Dialogue_-_ Archives_at_the_Crossroads1.pdf (07. 08. 2019).

25 Carolyn Hamilton / Verne Harris / Sello Hatang: Fashioning Legacy in South Africa. Power, Pasts and the Promotion of Social Cohesion, in: Peter Kearns / Sofia Kling / Christina Wistman (eds.): Heritage, Regional Development and Social Cohesion, Östersund 2011, pp. 146-159.

26 Workshop: Truth, Reconciliation and Transparency in South Africa and Kenya. Lessons learned, Johannesburg, 4 April 2009, Goethe Institut, Nelson Mandela Foundation and Rosa Luxemburg Foundation, online: https://www.nelsonmandela.org/uploads/ files/Truth,_Reconciliation_and_Transparency_in_SA_and_Kenya.pdf (28. 09. 2019).

27 Kerry Tanner: Survey Research, in: Kirsty Williamson (ed.): Research Methods for Students, Academics and Professionals. Information Management and Systems, Waga 2002, pp. 89-109, at p. 91.

28 Gary T. Henry: Practical Sampling, Newbury Park, 1990, p. 17.

29 Martyn Denscombe: The Good Research Guide for Small-scale Social Research Projects, Maidenhead, Berkshire 2007, p. 17.

30 Zina O'Leary: The Essential Guide to Doing Research, Newbury Park, CA 2004, p. 153.

31 Tanner: Survey Research, p. 97.

32 Denscombe: The Good Research, p. 175.

33 Dawson R. Hancock / Bob Algozzine: Doing Case Study Research. A Practical Guide for Beginning Researchers, New York 2006, p. 40.

34 Candice Glossoti: Independent Benchmarking Exercise Phase 2. Internal document, Johannesburg: Nelson Mandela Foundation 2006.

35 NMF business plan 2007-2011.

36 Shadrack Katuu / Verne Harris / Sello Hatang: The Mandela Portal - Past, Present and Future, in: Journal of the South African Society of Archivists, 44 (2011), pp. 131-142.

37 Marianne Bojer / Heiko Roehl / Knuth Marianne: Mapping Dialogue. Essential Tools for Social Change, Chagrin Falls 2008.

38 Resolve Group et al.: Dialogue Research Report. Internal Document, Nelson Mandela Foundation, Johannesburg 2007.

39 Resolve Group: Dialogue research report, p. 9.

40 NMF business plan 2007-2011, chapter 8.

41 NMF business plan 2007-2011, p. 44

42 TNS South Africa: Awareness, Knowledge and Perceptions of the Nelson Mandela Foundation. Internal Document, Johannesburg 2009.

43 Katuu / Harris / Hatang: The Mandela Portal Archivists.

44 Katuu / Harris / Hatang: The Mandela Portal Archivists; Shadrack Katuu / Sello Hatang: The Mandela Portal. How Do Visitors Get There?, in: The Indexer 28/2 (2010), pp. 69-73.

45 Memory for justice. Report on a colloquium. 18. 08. 2005, Nelson Mandela Foundation, Johannesburg 2005; State of the Archives. An Analysis of South Africa's National Archival System, 2014, prepared by the Archival Platform, online: http://www.apc.uct.ac.za/apc/ projects/state-of-the-archives-report (07. 08. 2019); A Ground of Struggle. Four Decades of Archival Activism in South Africa, prepared by the Archival Platform, 2018, online: http://www.apc. uct.ac.za/apc/projects/a_ground_of_struggle (07. 08. 2019). 


\section{Abstract}

The Nelson Mandela Centre of Memory Project was launched by the former President Mandela in 2004 as a special project of the Nelson Mandela Foundation (NMF). In 2006, the Foundation's Board of Trustees decided to adopt the Centre as the Foundation's core operational function, a decision to be implemented in terms of a 5-year transition plan. In February 2012, the latter ended with a public announcement of the organisation's new mandate to work in the memorydialogue nexus and intention to unveil the Centre as a public facility in 2013. This fundamental organisational transition (with many subsidiary change management processes) was informed by four dedicated research interventions, all conducted within an overarching action research framing: an investigation of the smemory for justices tradition in South Africa and its possible institutional application by the NMF; a global benchmarking study of cognate institutions; a study of dialogue as an element of Mandela's legacy in relation to the memory-dialogue nexus; and a marketing and branding survey. Verne Harris and Shadrack Katuu provide an account of these interventions, highlighting in each case the research designs and subsidiary research and analysis techniques. The article begins with a tracing of relevant historical and archival contexts and concludes with an assessment of the organisation's change management process and the efficacy of the organisational research agenda.

\section{About the Authors}

Verne HarRis is an adjunct professor at the Nelson Mandela University and heads the Nelson Mandela Foundation's leadership and knowledge development processes. He served in South Africa's Truth and Reconciliation Commission and is a former Deputy Director of the National Archives. He has authored or co-authored five books, is the recipient of an honorary doctorate from the University of Cordoba in Argentina (2014) and held the Follet Chair at Dominican University (Chicago) in 2018-9.

Dr Shadrack Katuu completed his Undergraduate Degree in Kenya, Masters Studies in Canada and Doctoral Studies in South Africa. He has worked in Austria, Botswana, Canada, Kenya, South Africa, South Sudan and the US. He is a research fellow at the Department of Information Science, University of South Africa and has authored several dozen publications (http://goo.gl/sJ3qBG). 